\title{
Scholar-Administrators as Change Agents
}

\author{
Emily M. Janke
}

\begin{abstract}
Flexibility and readiness to change are not necessarily valued or recognized traits in higher education. Yet higher education is in a period of dramatic change, because of rapid change in scholarship and society. With this change in mind, I reflect here on the role and effect of scholaradministrators as agents of change.
\end{abstract}

Keywords: social change; society; college administration; higher education; scholarship; scholar-administrators; leadership

\section{Introduction}

The Coalition of Urban and Metropolitan Universities (CUMU) named its scholar-administrator award in honor of my esteemed colleague, Dr. Barbara Holland. She often shares a joke when she introduces herself to a new audience of faculty, staff, or administrators. She says, "Hi, I'm Barbara, and I study change in higher education. Some think that's an oxymoron." This joke is funny, if the point is not already obvious, because being flexible and nimble, organizationally speaking, is not a recognized, or even necessarily valued, characteristic of higher education.

Higher education is in a period of dramatic and broad change because it is tethered, necessarily and inextricably, to the trends and needs of scholarship and society, which is changing at unprecedented rates. Institutions face a greater connection to the global economy and internationalization of campuses and curricula. Our increasingly diverse students, faculty and staff engage campuses differently than in the past. Society demands greater accountability of public investments. A new economic sector of for-profit higher education has emerged spurring competition and marketization. Rapid technological innovations have transformed how knowledge is generated, accessed, and shared (Kezar, 2013, pp. 5-6). Higher education institutions have always been and continue to be "inextricably interlocked" (Boyer, 1996, p. 11), as they exist to serve the current and future needs of society. So as society changes, so too must higher education if it is to remain relevant.

If institutions of higher education are to keep pace with the rapid advances and changes, indeed, transformations, occurring in society and the environment more broadly, administrative leaders of all ranks must remain at the forefront of learning about new directions and strategies to effect the outcomes they demand. To ensure the relevance, and hence, vibrancy of our institutions, it is important that administrators and scholars learn with and from each other-in real time. Across disciplines, even applied ones like higher education and business, practitioners lament the long latency between idea and useful implementation, or the challenge of converting theory to practice (Van de Ven, 2007). To stay current with trends and experiences, we need to empower 
and enable administrators to become and be scholar-administrators transcending false separation between scholarly and administrative work and identities.

As the inaugural recipient of the Barbara A. Holland Award for Scholar-Administrator, I reflect on the role of scholar-administrators as change agents within their institutions and beyond.

\section{Scholar-Administrators}

It is difficult, if not impossible to define precisely who a scholar-administrator is, mostly because it is an identity that individuals tend to claim, more so than a formal role codified in job descriptions. I have gained no purchase on which to assert a single definition of this identity. For the purpose of this essay, however, I focus on the definition provided by the Coalition for Urban and Metropolitan Universities (CUMU), which highlights "both a scholarly approach to their administrative role" and which establishes "an integrated record of administrative leadership and high-impact scholarship that (shapes) ideas and actions within and beyond (an) institution" (application, 2019).

This description suggests that through integration of scholarship with administration, one can advance multiple goals synergistically. One can use scholarly approaches to improve one's understanding of the issues facing higher education and how best to navigate them. Furthermore, one can develop scholarship that can be shared with others, passing along insights learned from the scholarship and strategies for guiding change that may be helpful to administrators of other campuses.

While administration is an appointment or position that one assumes formally, scholarship is an activity that one pursues. Individuals who produce scholarship are scholars, and scholarship may develop across various roles (e.g., faculty and administrative roles). Scholarship stands on its core characteristics: it demonstrates current knowledge of the field/discipline, invites peer collaboration and review, is open to critique, is presented in a form that others can build on, and involves critical reflection of the work (Glassick, Huber \& Maeroff, 1997).

The CUMU framing of a scholar-administrator identity is valuable because it focuses squarely on the role of scholarship in administration - as a tool and strategy that shapes not only what we know, but also what we do as administrators. This characterization resonates across narratives I have found in the limited scholarship on those who identify as scholar-administrators, as well as my own. Scholar-administrators leverage the skill sets, perspectives, networks, and resources they possess - as scholars who continue scholarly approaches and agendas - in their administrative positions to push proactively for change.

\section{Change Agent}

For many scholar-administrators, they seek administrative positions because it affords them access to resources and networks that are necessary for change, and which may not be otherwise possible, for example, as a faculty member within an academic department. In my own experience, I pursued administrative positions solely upon earning my doctorate because I wanted to build systems of support and encouragement that would increase the number of 
students and faculty engaged with communities through mutually beneficial and reciprocal partnerships. Since then, through administrative roles, I have accessed to tools of leadership and organizational development, namely funding, membership in decision-making teams and committees, power to recruit and convene, and the time needed to wake up every day focused on achieving the administrative agenda set forth. Working within an office focused on institutionalizing community engagement through building supportive policies, practices, and cultures among faculty, staff and students, I work with people across disciplinary and institutional silos. While my colleagues in faculty roles have limited time to push forward a community engagement agenda for the institution, it is my primary work. My view is expansive; I am working to transform the university, and higher education, more broadly.

\section{Reading the Changing Landscape}

Every discipline and administrative area is constantly evolving, due to changing conditions and new understandings. Therefore, it is essential for administrators to be constantly looking on the proverbial horizon, to help understand what is to come, and to plan how best to prepare the institution for that future. Hence, scholar-administrators are constantly on the steep end of the learning curve of new trends, technologies, and strategies. We read relevant literature and engage in national conversations so that we understand the issues and opportunities that will arise for our institutions.

In her article, "Change as a Scholarly Act: Higher Education Research Transfer to Practice," Ramaley describes the necessity of administrative leadership to actively pursue new areas of inquiry and scholarship, describing areas of scholarship that are far different from her training as a biologist. These include the areas of women and minorities in academia, university-industry partnerships and technology transfer, fundraising, team building and professional growth of staff, community college and high school articulation, enrollment management and student success, and conflict resolution.

She goes on to argue that "an administrator today must also be a learner among learners, willing to embrace the novel and unexpected and able to be an agent for change. To do this, we (scholaradministrators) must model what it means to have a truly educated mind and then use this mind in public. We must constantly study our environment and test various ideas, let us call them hypotheses, in the living laboratory over which we preside. It would be wise for us to apply to ourselves the same expectations that we have of any well-educated person... to employ a rigorous scholarly approach. (p. 76)

As a three-time university president, Ramaley embodies the approach of a scholar-administrator. She maintains a sense of curiosity about why and how things work, and then collaborates with individuals across a broad array of areas to identify new areas for collective learning. We need scholar-administrators because they are not satisfied to learn about ideas from others, repeating them on their own campuses, but instead seek to frame the questions themselves, engage in rigorous inquiry, and assess situations for themselves, integrating lessons learned from scholarship and their own administrative practice. In my own decade-long work as an administrator for community engagement, I have had to learn about many new topics that, at first, seem unrelated to community engagement. Often, I had to move across disciplinary and 
administrative silos, interpreting and adapting ideas and tools for use in my context. I have collaborated with many different people across many different roles and institutions to improve not only my, but collective understanding of the issues we face. Many of the areas of scholarship that Ramaley lists are still relevant nearly two decades later, but also have grown to include newer ones such as,

Ways of Knowing:

- Inter- and trans-disciplinary scholarship;

- cross-sector partnerships and anchor institutions to support collective impact (Kania \& Kramer, 2011; Taylor \& Luter, 2013; Vortuba, et al., 2002);

- Development of inter-institutional collaborations and shared cyber-infrastructure to support community-level data collection and use to improve services, programs, and quality of life;

Scholarly Communications:

- New and diverse forms of products and artifacts of knowledge generation, (Eatman, 2012, 2014), pluralistic forms of scholarly impact (Aguinis, Shapiro, Antonacopoulou, \& Cummings, 2014), and platforms for scholarly communications (Kramer \& Bosman, 2016; Narock et. al, 2019);

- Scholarly use of social media and altmetrics (Sugimoto, Work, Larivière, \& Haustein, 2017);

- Open data, open access, and open scholarship (Kramer \& Bosman, 2018; National Academies of Sciences, Engineering, and Medicine, 2018);

Diversity, Equity and Full Participation:

- Expanding the range of faculty and non-faculty positions and roles (e.g., non-tenure track teaching-focused and/or research-focused faculty; scholar-administrators) (Kezar, 2012);

- Policies, practices, and structures to support the full participation of diverse faculty, staff, and students (Sturm, Eatman, Saltmarsh, \& Bush, 2011); and

New Institutional Structures:

- Divisional models rather than departmental structures to organize faculty lines, curricula, and academic focus areas (Silverman, 2019).

Just these few major transitions and transformations are already underway on our campuses. These have required me to engage in the scholarly practices I describe. For example, I have read widely across different disciplinary and administrative areas to gain different perspectives on these topics. I have conducted interviews, focus groups, and surveys to gain a sense of campus climate on various issues to understand faculty members' knowledge, values, attitudes and behaviors related to various topics. I co-designed a database for tracking and measuring community engagement activities and partners so that our institution could have a better sense of our faculty and staff members' engagement with external communities so that we could better align community-university talents and priorities. 
The tools that scholar-administrators use to view the landscape, therefore, are the tools of a scholar. When necessary, they develop new lines of inquiry and research to improve understanding and practice. The administrator acts as a researcher as well as a leader of change (Holland, 2019, personal communication).

\section{Studying Leading Change}

Some forms of scholarship produced by administrators allow administrators to learn from each other about how to create conditions for change, as well as what needs to be changed. Studying the change process: what changed, who affected the change, how the change came about, and to what ends the change yielded is an essential aspect of being a change agent. To do this, they must not only stay current with issues, trends, and current events to help identify what changes need to occur. They also need to hear about best practices and innovations tried at other institutions, and, perhaps, based on the lessons of others, resist unproven changes that will not advance, or worse, will harm the mission, viability, and vibrancy of their institution if adopted (Kezar, 2014).

Little has changed since Cohen and March (1974) first described the factors that make change difficult in higher education. As a system, it has many ill-defined, often inconsistent, goals. Furthermore, it is comprised of members who vary concerning their level of time and personal investment in the organization. "Despite new policy and funding frameworks for education at the state and federal levels, higher education has largely tried to cope without changing core organizational practices and cultures. The sector has been slow to adapt to new conditions and expectations (Holland, 2019, p. 68, emphasis added). Seeing change coming is the easy part, it is organizing people and reorganizing structures and cultures that are most difficult.

Through their scholarly approach and sharing of scholarship, administrators build not only new understanding, but as importantly, relationships and trust. As they work with co-authors and share their work with colleagues, they develop personal relationships and social rapport. They find individuals who share similar passions for shared areas of inquiry, and they demonstrate to faculty that they understand what it takes to be a scholar and produce scholarship. They can appreciate the full process of scholarship, from inception to writing to dissemination and all of the steps in-between. When they attend academic conferences to present on their scholarly efforts, they sit alongside other faculty and scholar-administrators who are seeking to stay current with trends, pressing issues, and future directions for advancing various fields of scholarship. More importantly that the scholarship itself, most certainly, is the many different connections and relationships made among scholar-administrators and faculty through producing and sharing scholarship.

Any administrator who has been tasked to lead a new initiative knows that achieving success as change agents cannot be achieved by individuals or policies alone; "Being a successful change agent requires a broad and expansive view of leadership... to include members of all groups" (Kezar, 2014, p. 110). Such relationships make it easier to gain informal feedback on ideas, gain buy-in, and build coalitions for change. 
The composition of the faculty and staff in higher education is changing dramatically, and with it, expectations are changing as well. This demographic transition provides ripe opportunity for working alongside new cadres of colleagues who are similarly interested in transforming aspects of higher education so that they are more relevant and aligned to the needs of society and scholarship. Holland (2019) points out that higher education is now comprised of four generations of faculty and staff, from Baby Boomers to Gen Xers, to Millennials, to Gen Ys, and that these different generations have different profiles and expectations of academic work and professional life (Kezar \& Maxey, 2015; Trower, 2012). The faculty and instructor demographic profiles, trending similarly to but more slowly than national and student profiles, are becoming more diverse with regards to race, ethnicity, sexual orientation, gender identity, and generational culture.

These different individuals have different ideas about their sense of purpose, such as why they are scholars and what it means to be a scholar. They also view scholarship more expansively in terms of who produces scholarship, whom scholarship is for, and what aims scholars intend to influence and impact. No less, they tend to value and produce many diverse expressions of scholarship that are manifest in different types of products, shared on platforms that maximize the potential that their work will be viewed and used by the audiences and partners they have identified. No less, they believe in measuring the "impact" of one's contributions through scholarship in ways that go beyond more traditional notions of citation counts and publisher prestige (see Aguinis, Shapiro, Antonacopoulou \& Cummings, 2014 and Alperin, et al, 2019.).

\section{Sharing Change Strategies}

Scholar-administrators share their change strategies with others as a way to advocate for change within and across institutions. To do that, they do what other scholars do: they think, create, and share. In scholarly terms, they present and publish their work. Their work does not end once they have accomplished a goal; they share what they have done broadly and critically.

My own scholarly record reflects this. For the past decade, I have co-produced diverse artifacts of scholarship about the change processes that occurred at the University of North Carolina Greensboro's campus, about integrating recognition for community engagement into the faculty promotion and tenure guidelines. I have co-authored presentations, journal articles, book chapter, websites, datasets, workshops, surveys, reports, and other forms of scholarship, some of which has been peer-reviewed by other scholars, and nearly all of which is available on public platforms for broad and free access. I strive to share my scholarly work because I have benefited from learning with and from others. I want my learning to contribute to the collective learning about these topics we study so that the field can advance more effectively and quickly. An essential, but sometimes overlooked, practice of the scholar-administrator is that of producing scholarship: artifacts that are presented to others, so that the ideas may be reviewed, critiqued, and built upon.

Just as faculty are increasingly publishing and sharing new forms of scholarly communications (e.g., digital scholarship, data sets, digital archives, etc.), scholar administrators are also contributing new forms of scholarship. When scholar-administrators create and share data sets, videos/films, websites, blogs, social media feeds, reports, programs, manuscripts, exhibits, 
programs, and webinars, as well as performances, technical reports, program evaluations, curriculums, patents, and exhibits that are firmly grounded in the standards of high-quality scholarship - then they are producing scholarship. If one considers scholarship as residing along a continuum of approaches and artifacts, and which uphold the standards of scholarship, then scholar-administrators can situate their unique contributions of diverse forms of scholarship to the larger field of practice and research (Janke, 2019).

\section{Challenges of Being a Scholar-Administrator}

A scholarly approach to administration (i.e., the use of research, inquiry, evidence and other ways of examining and understanding systems of change) is not an intellectual exercise for the personal benefit of the scholar. However, the academic world, too often, treats this work as though it were. To be clear, many of my scholar-administrator colleagues relate that they are neither asked to nor rewarded for producing scholarship. They do scholarly administrative work in spite of the lack of recognition, and sometimes, disincentives for scholarship (Post, Ward, Longo, \& Saltmarsh, 2016). Lina Dostilio currently serves as associate vice chancellor for community engagement at the University of Pittsburgh. She has also, among other scholarly work, edited a book, authored a book, and served in fellowship positions to advance research and administrative agendas at the request of two national associations (Campus Compact and the CUMU), shares of her experience as a scholar-administrator at a previous institution:

My choice to maintain a scholarly agenda is also outside the norm for most administrators. As a result, my scholarship is not a main thrust of my administrative position, but is seen as a beneficial byproduct. Scholarship is the work I do early in the morning or late at night after my child is asleep. It is not the work I can do amid the chaotic phone calls, meetings, and e-mails of an engagement administrator. Yet, without research, my practice loses its focus and begins to cede the larger reason for why it exists. That larger vision, of leveraging higher education to address injustice, is compelling and sees me through to a stronger identity as a boundary spanner and community-oriented scholar. (Dostilio, Janke, Miller, Post, \& Ward, 2016, pp. 125-126, emphasis added)

Many scholars repeat this story of the importance, indeed, the necessity, of maintaining a scholarly agenda as an administrator for the sake of the administrative practice of serving as a change agent. Bickford and Whisnant's (2010) informal count at their large university revealed:

At least 40 such administrators, roughly three-quarters women. Many of us continue to pursue our scholarly research, writing, publication, public speaking, public engagement, and teaching while fulfilling our administrative duties... Academe has no system to recognize and encourage our unique contributions. (para. 3)

A review of administrative positions shows that policies and practices do not recognize the time and resources required for scholarly-administration. Scholar-administrators are too often not provided the resources, often in the form of access to data and the time and talents required to analyze the data (Ramaley, 2000). 


\section{Learning Organizations}

We ignore the scholarship of scholar-administrators to the detriment of institutions and system of higher education, as they are critical for supporting and effecting changes that are and will be required in order that higher education remains relevant, valued, and viable as a public good. Theories about organizational learning solving suggest that in order for institutions to change, they must provide change agents and other members with time and skills for reflection and professional support to develop personal competencies such as how to create a shared vision and facilitate team dialogue, and they must emphasize systematic inquiry and problem solving (Kezar, 2013).

Despite the importance of learning, however, many organizational leaders do not realize that such learning deserves support. Furthermore, it can be easily and unwittingly thwarted by policies, practices, and doubts that change is, in fact, possible (Kezar, 2013). For example, Bickford and Whisnant (2010) recount, "Those academic departments and administrative offices inclined to make more generous or flexible arrangements for us [scholar-administrators] lack precedents, policies, structures, and money for doing so" (para. 7). Even though one might expect institutions of higher education to be paragons of higher learning, which are supportive of professional development opportunities to foster creativity, innovations and visionary thinking, organizational learning is not a common phenomenon (Argyris, 1991). The previous examples suggest that this is so.

Hence, we must rethink and create awareness about the importance of the cyclical cycle of scholarship and administrative practice. Scholarship is integral to the work that scholaradministrators do, and, likewise, administrative work advances scholarship. Though the cycle is generative, it is not self-evident: time and resources must be provided to ensure that scholaradministrators are able to foster their scholarship as part of their work expectations. This means that scholarship, to use a recipe metaphor, is not an "additive" but is rather, "baked in" as an integral ingredient in the recipe for scholar-administrator success. This also means establishing criteria for recognizing and rewarding the various scholarly artifacts produced by scholaradministrators in personnel evaluations, creating clear guidelines for expectations from both the supervisor to support and the scholar-administrator to conduct scholarship.

\section{Building a Cadre of Scholar-Administrators}

I have written previously about the resonance that Rhoades and colleagues' (2008) writing about expectations of new and diverse faculty has had on my own thinking: they come not to "make it" in the academy, but to "remake" the academy. I have come, likewise, to understand that scholaradministrators, of the type that I have described in this essay, seek not to reify and uphold the academic structures and cultures that they inherited, but rather, to create and hold spaces in which these new scholars can arrive, persist, and thrive. The role of the scholar-administrator, then, is to stand shoulder-to-shoulder with other innovators, working towards transformation of our disciplines, our institutions, and higher education systems more broadly. This form of leadership encourages, cultivates, and, where necessary, protects scholars. 
What does a scholar-administrator need to be successful? By successful, I mean to help institutions of higher education remain flexible and vibrant in rapidly changing environments. We must move from idealistic encouragement of scholar-administrators, a theoretical stance not often accompanied by the structural space to practice scholarship, to a very practical, logistical effort of introducing policies and structures for encouraging the types of contributions we need from scholar-administrators. Such reform of policies, structures, and practice must begin to effectively recognize and reorganize conceptions about who is a scholar and what constitutes scholarship. The following list provides some recommendations for institutions of higher education as well as disciplinary and professional associations:

Institutional-Level Changes

1. Structure positions, expectations, and funding to allow scholar-administers to:

a. Review the base of evidence;

b. Establish their own theories of change;

c. Allot and protect time in administrative work schedules ("on the clock") for writing and the "deep work" (Newport, 2016) required to read, reflect, and produce scholarship to be shared with others;

d. Participate in regional, national, and international conversations, and translate them for local discussions and decision-making;

e. Proactively network and collaborate with other scholars for the purpose of collecting, generating, and sharing learning and scholarship, remotely and inperson;

f. Plan for scholarly work in annual work plans, reports, and reviews; and

g. Recognize and reward scholarly work and artifacts when evaluating accomplishments and making determinations about annual review accomplishments, merit pay, and promotions.

2. Recognize the scholarly accomplishments of scholar-administrators in similar ways to faculty accomplishments, including recognitions in campus-wide communications, awards, recognitions, and celebrations.

3. If the scholar-administrator has a faculty line or affiliation, include space in annual reporting documents and conversations to include activities and accomplishments related to scholarly administration so that such scholarship is recognized as an integrated aspect of the scholar-administrators profile.

Disciplinary- And Professional Association-Level Changes

4. Use existing and create new online, digital, and open access platforms for sharing the scholarship of academic change.

5. Carve out or establish new venues for diverse forms of scholarly artifacts, including, and beyond manuscript-form articles, generated by or used within administrative work. Consider the role of peer-review and how this may be different for scholarship and artifacts intended primarily for administrative audiences.

6. Recognize and celebrate excellence in scholar-administration, like the Barbara Holland Scholar-Administrator Award given by CUMU. 
This list will continue to develop and evolve as the environment continues to change as well.

\section{Conclusion}

The future of higher education will be led and populated by people we have not yet met, and they will address issues we have not yet encountered that will require knowledge, skills, and approaches we yet to imagine or invent. The need for higher education to change is inevitable if it is to stay current and relevant to needs and demands of society. Fortunately, we have in our midst a growing cadre of scholar-administrators who believe in the transformative power of higher education for students and society, and the ability of higher education to transform itself. These individuals span rank, position, discipline, and demographic.

It is time to better recognize and support the role of scholar-administrators as key change agents on our campuses. They are critical to supporting the work of others pursuing new ideas, emerging technologies, and expanding approaches to generating scholarship. Scholaradministrators are key partners in helping institutions of higher education transform their policies, practices and cultures because they possess both the tools of administration and research. They are practitioners, who understand the internal working of administration and who have networks of collaborators across disciplines, units and institutions. They have the passion for change, and they are forces of change. It is time, then, to recognize, prepare and support scholar-administrators more effectively, so that they can do what they do so well: serve as key change agents in and of higher education, and lead boldly into a yet-to-be defined future.

\section{Acknowledgements}

The author wishes to thank Drs. Barbara A. Holland, Terri L. Shelton, and Lina D. Dostilio for their continued inspiration as models of scholar-administrators, as well as for their conversations and feedback that have informed many of the ideas presented in this essay.

Within all of my research on change, leadership emerges as perhaps the most important facilitator, for without change agents' energy and enthusiasm, there would be little change. (Kezar, 2014, p. 108, emphasis added) 


\section{References}

Aguinis, H., Shapiro, D., Antonacopoulou, E. P., \& Cummings, T. (2014). Scholarly impact: A pluralistic conceptualization. Academy of Management Learning and Education, 13(4), 623-639. https://doi.org/10.5465/amle.2014.0121

Alperin, J. P. Muñoz Nieves, C., Niles, M., Schimanski, L. A., Fischman, G. E., Niles, M., \& McKiernan, E. (2019). How significant are the public dimensions of faculty work in review, promotion, and tenure documents? eLife. Preprint. https://doi.org/10.7554/eLife.42254

Argyris, C., \& Schön, D.(1995). Organizational learning: Theory, method and practice. New York, NY: Addison-Wesley.

Ball, C., Barrett, K., Berkery, P., Clemons, J., Crosby, S., Falk-Krzesinski, H. J., \& Konkiel, S. (2017). Promotion \& Tenure Reform Workgroup report: Promoting openness in professional advancement practices. Open Scholarship Initiative Proceedings, 2.

https://doi.org/10.13021/G8osi.1.2017.1928

Boyer, E., (1996). The scholarship of engagement. Journal of Higher Education Outreach and Engagement, 1(1), 11-20. https://doi.org/10.2307/3824459

Brown, J. S., \& Duguid, P. (1991). Organizational learning and communities-of-practice:

Toward a unified view of working, learning and innovation. Organization Science, 2(1), 40-57. https://doi.org/10.1287/orsc. 2.1 .40

Cohen, M. D., \& March, J. G. (1974). Leadership and ambiguity: The American college president. New York, NY: McGraw-Hill.

Eatman, T. K. (2012). The arc of the academic career bends toward publicly engaged scholarship. In A. Gilvin, G. M. Roberts \& C. Martin (Eds.), Collaborative futures: Critical reflections on publicly active graduate education (pp. 25-48). Syracuse, NY: The Graduate School Press.

Eatman, T. K. (2014). Expanding the continuum of knowledge-making. In Janke, E. M., Medlin, K. B, \& Holland, B. A. Honoring the mosaic of talents and stewarding the standards of high quality community-engaged scholarship. Excellence in Community Engagement \& CommunityEngaged Scholarship (vol. 2). Greensboro: Institute for Community and Economic Engagement, University of North Carolina at Greensboro.

Geiger, R. (2016). The history of American higher education: Learning and culture from the founding to World War II. Princeton, NJ: Princeton University.

Holland. B. (2019). Factors influencing faculty engagement. In L. R. Sandmann \& D. O. Jones (Eds.). Building the field of higher education: Foundational ideas and future directions (pp. 6372). Sterling, VA: Stylus. 
Kania, J., \& Kramer M. (2011, Winter). Collective impact. Stanford Social Innovation Review, 2011(Winter), 110. Retrieved from https://ssir.org/articles/entry/collective impact

Kezar, A. (2013). How colleges change. New York, NY: Routledge.

Kezar, A. (Ed.). (2012). Embracing non-tenure track faculty: Changing campuses for the new faculty majority. New York, NY: Routledge.

Kezar, A., \& Maxey, D. (Eds.). (2016). Envisioning the faculty for the twenty-first century: Moving to a mission-oriented and learner-centered model. New Brunswick, NJ: Rutgers.

Kramer, B., \& Bosman, J. (2016). Innovations in scholarly communication - global survey on research tool usage [version 1; peer review: 2 approved]. F1000Research, 5. https://doi.org/10.12688/f1000research.8414.1

Kramer, B., \& Bosman, J. (2018, January 14). Rainbow of open science practices [digital image]. Zenodo. http://doi.org/10.5281/zenodo.1147025

Narock, T., Goldstein, E. B., Jackson, C., Bubeck, A., Enright, A., Farquharson, J., ... Ampuero, J. P. (in press). Earth science is ready for preprints: The first year of EarthArXiv. Eos.

Preprint. https://doi.org/10.31223/osf.io/kftsv

National Academies of Sciences, Engineering, and Medicine. 2018. Open Science by Design: Realizing a Vision for 21st Century Research. Washington, DC: The National Academies Press. https://doi.org/10.17226/25116.

Newport, C. (2016). Deep work: Rules for focused success in a distracted world. London, UK: Hachette.

Ramaley, J. (2017). Facilitating change: Experiences with the reform of STEM education. Retrieved from http://citeseerx.ist.psu.edu/viewdoc/summary?doi=10.1.1.526.8592.

Rhoades, G., Kiyama, J. M., McCormick, R., \& Quiroz, M. (2008). Local cosmopolitans and cosmopolitan locals: New models of professionals in the academy. The Review of Higher Education, 31(2), 209-235. https://doi.org/10.1353/rhe.2007.0079

Schön, D. A. (1983). The reflective practitioner: How professionals think in action. New York, NY: Basic Books.

Silverman, A. (2019). The multidisciplinary reorganization toolkit: Guidance and resources for transitioning from siloed departments to a collaborative academic governance model. Washington, DC: Educational Advisory Board. Retrieved from https://www.eab.com/researchand-insights/academic-affairs-forum/toolkits/multidisciplinary-reorganization-toolkit 
Sturm, S., Eatman, T., Saltmarsh, J., \& Bush, A. 2011. Full participation: Building the architecture for diversity and public engagement in higher education [White paper]. New York, NY: Columbia University Law School, Center for Institutional and Social Change.

Sugimoto, C. R., Work, S., Larivière, V., \& Haustein, S. (2017). Scholarly use of social media and altmetrics: A review of the literature. Journal of the Association for Information Science and Technology, 68(9), 2037-2062. https://doi.org/10.1002/asi.23833

Taylor, H. T., \& Luter, G. (2013). Anchor institutions: An interpretive review essay. New York: Anchor Institutions Task Force. Retrieved from http://www.margainc.com/initiatives/aitf/

Trower, C. (2006). Gen X meets Theory X: What new scholars want. Journal of Collective Bargaining, 0, Article 11. Retrieved from http://thekeep.eiu.edu/jcba/vol0/iss1/11

Urban Universities for HEALTH. (2015). Faculty cluster hiring for diversity and institutional climate. Retrieved April 12, 2019 from

http://urbanuniversitiesforhealth.org/media/documents/Faculty_Cluster_Hiring_Report.pdf

Van de Ven, A. H. (2007). Engaged scholarship: A guide for organizational and social research. Oxford, UK: Oxford University.

Vortruba, J. C., Bailey, J. I., Bergland, B. W., Gonzalez, A., Haynes, K. S., Howard, M. A., ... \& Siegel, B. L. (2002). Stepping forward as stewards of place: A guide for leading public engagement at state colleges and universities. Washington, DC: American Association of State Colleges and Universities.

Weerts, D. J. (2011). "If only we told our story better...": Re-envisioning state-university relations through the lens of public engagement (WISCAPE Viewpoints). Madison: Wisconsin Center for the Advancement of Postsecondary Education. Retrieved from https://eric.ed.gov/?id=ED518998 


\section{Author Information}

Emily M. Janke

Institute for Community \& Economic Engagement

UNC Greensboro

1111 Spring Garden Street

Greensboro, NC 27412

Telephone: (336) 256-2578

Email: emjanke@uncg.edu

Emily M. Janke, Ph.D. is director of the Institute for Community and Economic Engagement (ICEE) and an associate professor in the Peace and Conflict Studies department. As the Director of ICEE, Emily leads and supports initiatives that encourage, support, elevate, and amplify faculty, staff, student, and community colleague community-engaged teaching, learning, research, creative activity, and service. Emily's scholar-administrative work addresses multiple aspects of community engagement focused on community-university partnerships, and institutional culture and change strategies. In particular, she focuses on tracking and measuring community engagement and public service within and across institutions of higher education, the recognition of community-engaged scholarship in reappointment, promotion and tenure policies; the role of conflict management and transformation in community-university partnerships; institutional support for community engagement; innovations in scholarly communications; and reciprocity, collaborative communication, and restorative practices as aspects of high quality, ethical community engagement. 